\title{
Laparoscopic Versus Open Laparotomy in Management of Intestinal Malrotation and Volvulus in Neonates: A Comparative Study
}

\author{
Omar Atef Elekiabi ${ }^{*}$, Ehab M Oraby ${ }^{2}$, Tamer Wasefy ${ }^{3}$ and Ahmed K El- Taher ${ }^{3}$ \\ ${ }^{1}$ Department of Pediatric Surgery, Faculty of Medicine, Zagazig University, Zagazig Egypt \\ ${ }^{2}$ Department of General Surgery, Faculty of Medicine, Benha University, Benha Egypt \\ ${ }^{3}$ Department of General Surgery, Faculty of Medicine, Zagazig University, Zagazig Egypt \\ *Corresponding Author: Omar Atef Elekiabi, Department of Pediatric Surgery, Faculty of Medicine, Zagazig University, Zagazig Egypt.
}

Received: September 25, 2019; Published: October 05, 2019

DOI: $10.31080 /$ ASGIS.2019.02.0086

\begin{abstract}
Background: Ladd's procedure is the preferred method of management of Intestinal malrotation and could be performed either by laparotomy or by laparoscopy. A number of studies have described successful management of malrotation using laparoscopic approach. But there are few reports about the safety and feasibility of malrotation management using laparoscopy during the neonatal period.

In the present study we aimed to compare the clinical outcomes of a group of neonates with intestinal malrotation and volvulus who underwent laparoscopic assisted surgical management with a similar group of patients subjected to the classic open Ladd's approach.

Materials and Methods: The current study included thirty neonates who were suspected to have intestinal malrotation and volvulus and underwent surgery in the period from May 2016 to July 2019. We divided our patients into two groups each group included fifteen neonates the first group underwent laparoscopic assisted surgery and the second group underwent classical open Ladd's approach. We evaluated the patients to detect the clinical outcome.

Results: There were no statistically significant differences between both groups regarding; age or sex of the patients, weight at surgery, comorbidity or primary presentation. The operative time for the first group was longer than operative time for the second group ( $\mathrm{P}=0.021$ ). The duration of hospital stay and duration of starting full oral diet for the first group was shorter than that for the second group $(\mathrm{P}<0.001)$.

Conclusion: laparoscopy is a safe, effective and feasible approach for surgical management of intestinal malrotation with volvulus in newborns and children when compared to classical open Ladd's procedure.

Keywords: Volvulus; Intestinal Malrotation; Neonates; Ladd's Procedure; Laparoscopy
\end{abstract}

\section{Introduction}

Intestinal malrotation is the name for a variety of intestinal attachments and rotation abnormalities that ranged from a mobile cecum to a complete non-rotation of the intestine with or without an associated volvulus of the midgut and reversed rotation. Patients present with midgut volvulus as a complication of intestinal malrotation during the 1 st year of life, mostly within the first seven days [1].

Newborns with intestinal malrotation mostly present with a scaphoid abdomen and bilious vomiting which is associated with midgut volvulus, which leads to serious outcomes in case of a delay in diagnosis and treatment [2]. Ladd in 1938 described a surgical approach for management and is still the main line of management of malrotation [3]. Ladd's procedure could be performed either by laparotomy or by laparoscopy and it consists of intestinal derotation, mesenteric base widening and division of Ladd's bands if needed. A number of serious has described successful management of malrotation using laparoscopic approach, since the first studies done in $1998[4,5]$.

But there are a few reports about the safety and feasibility of malrotation management using laparoscopy during the neonatal period (0-forty days of life).

In the present study we aimed to compare the clinical outcomes of a group of neonates with intestinal malrotation and volvulus who underwent laparoscopic assisted surgical management with a similar group of patients subjected to the classic open Ladd's approach. 


\section{Materials and Methods}

The current study included thirty neonates who were suspected to have intestinal malrotation and volvulus and underwent surgery in Pediatric Surgery Department, Faculty of Medicine, Zagazig University, in General Surgery Department, Faculty of Medicine, Benha University and in in General Surgery Department, Faculty of Medicine, Zagazig University in the period from May 2016 to July 2019 in the period from May 2016 to July 2019.

We divided our patients into two groups each group included fifteen neonates the first group underwent laparoscopic assisted surgery and the second group underwent classical open Ladd's approach. We evaluated the patients to detect the clinical outcome.

The indication for surgical intervention was based on clinical findings and radiological investigations. We recorded all clinical data of patients include patients' age, sex; presenting symptoms, associated malformations, imaging, line of surgical management, and clinical patients' outcome.

\section{Inclusion criteria}

Neonates with clinical and radiological evidence of intestinal malrotation.

\section{Exclusion criteria}

Patients who were septic, with electrolyte imbalance, hemodynamically unstable, with bleeding per rectum, gangrenous bowel caused by volvulus and patients with severe cardiac or other congenital anomalies as congenital diaphragmatic hernia.

\section{Surgical technique of laparoscopic surgery}

We placed the child in supine position with head end up for laparoscopic surgery, using three $5 \mathrm{~mm}$ trocars initially and with two $3 \mathrm{~mm}$ trocars later on for instruments.

We placed the monitor at the head end on right side of the patient and placed the anesthesia work station on the left. Surgeon stood on the right side, of the patient, cameraman on to the left side of surgeon and the assistant stood on the right side of the surgeon.

We created carbo-peritoneum, using open method through insertion of the first $5 \mathrm{~mm}$ trocar at the umbilicus. We inserted three additional three mm ports under laparoscopic guidance, one at left mid-clavicular line at the umbilicus level and the second port is placed in the mid-clavicular region in the right side at the umbilicus level, then we inserted the a third port at the left subcostal region for colon retraction.

We examined the abdomen for the presence of volvulus, bowel viability and the malrotation type. We first divided Ladd's bands that lead to free mobility of cecum to allow derotation then we made the technique of 'steering wheel' derotation that involved rotation of the rotating cecum anticlockwise toward the right hy- pochondrium using right bowel grasper and using left as assistant, then we made anticlockwise rotation of the ileum to left hypochondrium. The next step is performing an anticlockwise rotation of the cecum to left hypochondrium, and then the last turn included anticlockwise ileum rotation to the right hypochondrium.

This approach could correct the $360^{\circ}$ volvulus easily. After performing the derotation, the cecum became in the left hypochondrium and duodeno-jejunal junction was located at the right side which is confirmed by appearance of visible releasing of the mesenteric twist. After performing derotation, the duodenum was straight and the mesentery became wide which safeguarded the mesenteric vessels to allow completing the Ladd's approach. We keep the nasogastric tube until the aspirate changed to gastric content. We started oral feeding one day after performed surgery for all patients and they were discharged after having full feeds.

\section{Surgical technique of open surgery}

We divided Ladd's bands, released the cecum and colon from the duodenum and pancreas medially. Straitened duodenum and jejunum loops, widened the base of mesentery, and performed appendectomy. We placed cecum and colon on the left side of midline then placed the straightened duodenum and small bowel on the right side.

We followed-up our patients for any post-operative or long term complications.

Concerning the statistical analysis, groups were compared either using a two-sample t-test for continuous variables or using Fisher's exact test for categorical variables. One-sided $\mathrm{P}$ values were calculated for the $95^{\text {th }}$ confidence interval, and those $\mathrm{P}$ values less than or equal to .05 were considered significant.

\section{Results}

\section{Patient characteristics}

Thirty patients underwent different surgeries for intestinal malrotation and volvulus fifteen. patients (group 1) were managed by laparoscopy and fifteen patients (group 2) were managed by open surgery. Detailed patient characteristics are summarized in Table 1.

The first group included14 (93.3) males and 1(6.7) females while the second group included 10 (66.7) males and 5(33.3) females. Mean age at surgery was $6.43 \pm 21.2$ days for the first group and $5.33 \pm 22.29$ days for the second group. There were no statistically significant differences between both groups regarding; age or sex of the patients, weight at surgery, comorbidity or primary presentation.

\section{Operative results}

The mean operative time for the first group was $70 \pm 60.75$ minutes (range, 35 - 190), the mean operative time for the second 


\begin{tabular}{|l|c|c|c|}
\hline \multirow{2}{*}{\multicolumn{1}{|c|}{ Variables }} & \multicolumn{2}{|c|}{ Management techniques } & \\
\cline { 2 - 3 } & Laparoscopy & Open surgery & \multirow{2}{*}{ p } \\
\cline { 2 - 3 } & N=15 (50\%) & N=15 (50\%) & \\
\hline Age at surgery (days): & & & \\
Mean \pm SD & $6.43 \pm 21.2$ & $5.33 \pm 22.29$ & 0.147 \\
Range & $3-36$ & $1-40$ & \\
\hline Sex: & $14(93.3)$ & $10(66.7)$ & \\
Males & $1(6.7)$ & $5(33.3)$ & 0.27 \\
Female & $14(93.3)$ & $12(80)$ & 0.08 \\
\hline Comorbidity: & $1(6.7)$ & $3(20)$ & \\
Absent & & & \\
Present & $3.43 \pm 1.2$ & $3.33 \pm 1.29$ & 0.147 \\
\hline weight at surgery & & & \\
(kg): & $3(20)$ & $4(26.7)$ & \\
Mean \pm SD & $11(73.3)$ & $12(80)$ & 0.542 \\
\hline Bilious vomiting (\%): & & & \\
Absent & & & \\
Present & & & \\
\hline $\begin{array}{l}\text { Disturbance of stool- } \\
\text { ing pattern (\%): }\end{array}$ & & & \\
Absent & & & \\
Present & & & \\
\hline
\end{tabular}

Table 1: Clinical and demographic findings of studied patients.

group was $50.67 \pm 33.67$ minutes (range, $25-150)$, $(P=0.021)$. We converted two patients in the first group (15\%) to an open procedure because of inability to expose the mesenteric vessels. We made resection of primary stoma in two cases in the first group. We performed midgut resection in 1 patient $(6.7 \%)$ from the first group with temborary stoma and in 3 patients (20\%) from the second group with primary resection. Operative findings of studied patients were detailed in table 2 .

\section{Postoperative outcome}

The mean duration of hospital stay was $8.83 \pm 5.75$ days for the first group and $15.77 \pm 5.04$ days for the second group $(\mathrm{P}<0.001)$. The mean duration of starting full oral diet was $4.87 \pm 2.99$ days for the first group and $7.2 \pm 6.63$ days for the second group $(\mathrm{P}<0.001)$. No recurrent volvulus or in-hospital death was noted. The postoperative data were detailed in Table 3.

\section{Discussion}

Midgut rotational abnormalities were referred to a wide range of intestinal mal-fixation and incomplete rotation during intrauterine development that resulted in mesenteric base narrowing, volvulus of the midgut and Ladd's bands formation of in newborn and young children [6]. The most popular management is Ladd's procedure which has various techniques; Agrawal., et al. [6], described 'steering wheel' technique to allow easy volvulus derotation. After the marked success of laparoscopic assisted surgical

\begin{tabular}{|c|c|c|c|}
\hline \multirow{3}{*}{ Variables } & \multicolumn{2}{|c|}{ Management techniques } & \multirow{3}{*}{$\mathbf{p}$} \\
\hline & Laparoscopy & Open surgery & \\
\hline & $\mathrm{N}=15(\%)$ & $\mathrm{N}=15(\%)$ & \\
\hline $\begin{array}{l}\text { Operative time } \\
\text { (minutes): } \\
\text { Mean } \pm \text { SD } \\
\text { Range }\end{array}$ & $\begin{array}{c}70 \pm 60.75 \\
35-190\end{array}$ & $\begin{array}{c}50.67 \pm 33.67 \\
25-150\end{array}$ & $0.021 *$ \\
\hline $\begin{array}{l}\text { Resection of mid gut } \\
(\%): \\
\text { Absent } \\
\text { Present }\end{array}$ & $\begin{array}{c}14(93.3) \\
1(6.7)\end{array}$ & $\begin{array}{l}12(80) \\
3(20)\end{array}$ & 0.542 \\
\hline $\begin{array}{l}\text { Appendectomy (\%): } \\
\text { Absent } \\
\text { Present }\end{array}$ & $\begin{array}{c}3(20) \\
12(80)\end{array}$ & $\begin{array}{c}2(15) \\
13(85)\end{array}$ & 0.542 \\
\hline $\begin{array}{l}\text { Conversion to open } \\
\text { surgery: } \\
\text { n (\%) }\end{array}$ & $2(15)$ & & \\
\hline
\end{tabular}

Table 2: Operative findings of studied patients.

\begin{tabular}{|c|c|c|c|}
\hline \multirow{3}{*}{ Variables } & \multicolumn{2}{|c|}{ Management techniques } & \multirow{3}{*}{$\mathbf{p}$} \\
\hline & Laparoscopy & Open surgery & \\
\hline & $\mathrm{N}=15(\%)$ & $\mathrm{N}=15(\%)$ & \\
\hline $\begin{array}{l}\text { Hospital stay } \\
\text { (days): } \\
\text { Mean } \pm \text { SD } \\
\text { Range }\end{array}$ & $\begin{array}{c}8.83 \pm 5.75 \\
7-20\end{array}$ & $\begin{array}{c}15.77 \pm 5.04 \\
15-50\end{array}$ & $<0.001^{* *}$ \\
\hline $\begin{array}{l}\text { Time to full diet: } \\
\text { days (range): } \\
\text { Mean } \pm \text { SD } \\
\text { Range }\end{array}$ & $\begin{array}{c}4.87 \pm 2.99 \\
3-8\end{array}$ & $\begin{array}{c}7.2 \pm 6.63 \\
12-18\end{array}$ & $<0.001^{* *}$ \\
\hline $\begin{array}{l}\text { Post-operative } \\
\text { emesis: n (\%): } \\
\text { Absent } \\
\text { Present }\end{array}$ & $\begin{array}{l}12(52.8) \\
3(28.6)\end{array}$ & $\begin{array}{c}12(47.2) \\
3(71.4)\end{array}$ & 0.424 \\
\hline $\begin{array}{l}\text { Redo surgery: } \mathrm{n} \\
\text { (\%): } \\
\text { Absent } \\
\text { Present }\end{array}$ & $\begin{array}{c}14(52.8) \\
1(28.6)\end{array}$ & $\begin{array}{c}13(47.2) \\
2(71.4)\end{array}$ & 0.424 \\
\hline
\end{tabular}

Table 3: Post-operative findings of studied patients.

management of malrotational intestinal anomalies in a neonate, number of laparoscopic surgeries has been markedly increased and its safety has been confirmed by recent studies $[1,2]$.

The conflict between laparoscopic and open approaches of performing Ladd's technique is still present.

In the present study we compared between both approaches of management to assess degree of safety and feasibility of lapa- 
roscopic assisted surgical management of Ladd's technique. We found that laparoscopic assisted surgical management of intestinal malrotation and volvulus in newborn is a feasible and easier procedure than open technique and these results were similar to previous studies which support using laparoscopic approach in management of malrotation in newborn and children as it is associated with patient comfort, formation of less adhesions and fewer complications of incisions [1,2,6-8].

Agrawal., et al. [6], showed that laparoscopic assisted 'steering wheel' derotation procedure is an easy method which provided a stepwise laparoscopic derotation of associated volvulus with intestinal malrotation in children.

Reddy., et al. [2], showed the safety of laparoscopic Ladd's approach of management of intestinal malrotation in newborn and children with or without volvulus. But, some of their cases needed conversion to open surgery because of their difficult anatomy.

The advantages of the laparoscopic method include an earlier full oral feeding and shorter duration of stay.

The disadvantages of an open Ladd's procedure include a higher incidence of postoperative adhesions and discomfort.

Regarding the perioperative outcome, we noticed significant differences in the operating time between both study groups we favor the laparoscopic approach due to shorter operating time which reduces further complications in newborns as there is a marked reduction of temperature of the body, lower incidence of postoperative ileus, and reduction in usage of narcotic. Additionally, we have noticed significant differences between both studied groups of patients in the duration of post-operative hospital stay and in duration to returning to full oral diet, which encourage laparoscopy usage in children with intestinal malrotation with or without volvulus.

But laparoscopy is still a controversial approach of management of such anomaly [10-12].

Different results shown by Zhu., et al. [13], who stated that in neonates, laparoscopic assisted Ladd's approach was found to be associated with a higher risk of volvulus recurrence (5\%) in comparison to the open procedure $(0.5 \%)$, which raised doubts about the safety and effectiveness of the laparoscopic approach in newborns.

Zhu., et al. [13], explained that many factors were incriminated in increasing the risk of having recurrent volvulus of midgut after performing laparoscopic Ladd's procedure, as the weight of the newborn and the presence of volvulus of midgut at first operation.

\section{Conclusion}

Our results showed that laparoscopy is a safe, effective and feasible approach for surgical management of intestinal malrotation with volvulus in newborns and children when compared to classical open Ladd's procedure.

\section{Bibliography}

1. Ferrero L., et al. "Intestinal Malrotation and Volvulus in Neonates: Laparoscopy Versus Open Laparotomy". Journal of Laparoendoscopic and Advanced Surgical Techniques 27 (2017): 318-321.

2. Reddy SA., et al. "Laparoscopic ladd's procedure in children challenges, results, and problems". Journal of Indian Association of Pediatric Surgeons 23 (2018): 61-65.

3. Ladd WE., et al. "Intestinal obstruction resulting from malrotation of the intestines and colon". In: Abdominal Surgery of Infancy and Childhood (1941): 53-70.

4. Lessin MS and Luks F. "Laparoscopic appendectomy and duodenocolonic dissociation (Ladd) procedure for malrotation". Pediatric Surgery International 13 (1998): 184-185.

5. Bass J., et al. "Laparoscopic Ladd's procedure in infants with malrotation". Journal of Pediatric Surgery 33 (1998): 279-281.

6. Agrawal V., et al. "Laparoscopic 'steering wheel' derotation technique for midgut volvulus in children with intestinal malrotation". Journal of Minima Journal of Minimal Access Surgery 15 (2019): 219-223.

7. Huntington JT., et al. "Comparing laparoscopic versus open Ladd's procedure in pediatric patients". Journal of Pediatric Surgery 52 (2017): 1128-1131.

8. Hagendoorn J., et al. "Laparoscopic treatment of intestinal malrotation in neonates and infants: retrospective study". Surgical Endoscopy 25 (2011): 217-220.

9. Tashjian DB., et al. "Outcomes after Ladd's procedure for intestinal malrotation with heterotaxia". Journal of Pediatric Surgery 42 (2007): 528-531.

10. Catania VD., et al. "Open versus laparoscopic approach for intestinal malrotation in infants and children: a systematic review and meta-analysis". Pediatric Surgery International 32 (2016): 1157-1164.

11. Isani MA., et al. "Is less more? Laparoscopic versus open Ladd's procedure in children with malrotation". Journal of Surgical Research 229 (2018): 351-356. 
12. Kinlin C and Shawyer AC. "The surgical management of malrotation: a Canadian Association of Pediatric Surgeons survey". Journal of Pediatric Surgery 52 (2017): 853-858.

13. Zhu H., et al. "Reoperation after Ladd's procedure in the neonatal period". Pediatric Surgery International 35 (2019): 117120.

\section{Volume 2 Issue 9 November 2019}

(C) All rights are reserved by Omar Atef Elekiabi., et al. 